\title{
Correlation of Depression with Edentulism in Elderly Patients
}

\author{
Kunal Kumar ${ }^{1}$, Vikas Vaibhav ${ }^{2}$, Abhinav K Singh ${ }^{3}$, Neal B Kedia ${ }^{4}$, Gunjan Kedia ${ }^{5}$, Sudhanshu Kumar ${ }^{6}$
}

\begin{abstract}
Aim: Loss of all natural teeth is termed as edentulism. In elderly population with edentulism, depression enhances the risk of poor oral health. Present research was done to assess edentulism in elderly patients and its correlation with depression.

Materials and methods: Present research comprised of 530 completely edentulous subjects. Personal Health Questionnaire-8 (PHQ-8) was subjected to all patients to evaluate the depression status. Parameters such as education, marital position, and socioeconomic position were also noted.

Results: There was 280 (52.8\%) males and 250 (47.2\%) females out of 530 patients; 280 (52.8\%) subjects had low socioeconomic status, 170 (32.0\%) had middle, and $95(17.9 \%)$ had high socioeconomic status. Total $275(51.8 \%)$ patients had education up to primary standard, 170 (32.0\%) had high, and 105 (19.2\%) had secondary standard. Total 502 (94.8\%) patients were married and $28(5.2 \%)$ were unmarried. All variables showed statistically significant difference $(p<0.05)$. Patient health questionnaire (PHQ-8) scoring and interpretation with behavioral risk factor surveillance survey (BRFSS) response conversion showed that most of the patients (60.2\%) had score more than 15 , which suggests that patients had depression symptoms. Edentulism was significantly associated with socioeconomic status $(\mathrm{OR} 1.02,95 \% \mathrm{Cl}=0.94-2.06)$, education level (OR 1.0, 95\% Cl = 0.98-1.72), marital status (OR 1.14, 95\% Cl =1.08-2.34), and depression (OR 1.50, 95\% Cl = 1.24-2.14).

Conclusion: It was observed in this study that edentulism was more predominant among patients with poor socioeconomic status, married, and patients with education level up to primary level. Maximum number of patients had depression symptoms, thus indicating correlation of depression with tooth loss.

Keywords: Depression, Edentulism, Psychiatric illness.

International Journal of Prosthodontics and Restorative Dentistry (2020): 10.5005/jp-journals-10019-1279
\end{abstract}

\section{INTRODUCTION}

Loss of all natural teeth is termed as edentulism. In elderly individual, it is the most prevalent situation. It has been observed to be present in $10 \%$ of population aged $>50$ years. ${ }^{1}$ It is also found in socially deprived young individuals. The number of edentulous patients increases exponentially, as there is raise in life anticipation in past several years. ${ }^{2}$

It has been observed that poor oral health may be the risk factor for coronary artery disease, cerebrovascular accidents (CVAs), and myocardial infarction. ${ }^{3}$ Factors such as education level, socioeconomic status, physical health, employment status, mental health, and availability of dental care play a significant part in causing loss of teeth. ${ }^{4}$ There is relationship between poor oral health and poor mental health, low self-esteem and poor quality of life. Edentulism has also been found to be more predominant in medically compromised elderly population. Edentulism directly distresses nutrition, facial appearance, speaking eating capacity, and social life. ${ }^{5}$

Depression is rather communal among aged people and there has been increase in cases over last couple of years. It has damaging effect on the oral health. Depression upturns the risk of poor oral health especially in elderly population. ${ }^{6}$ Subjects with psychiatric illness or depression are more prevalent to edentulism. Such subjects are unwilling to their oral health resulting in edentulism. They are on multiple drugs for the psychiatric illness or depression. ${ }^{7}$ Present research aimed to assess edentulism in elderly subjects and its correlation with depression.

\section{Materials and Methods}

This prospective research was conducted among 530 completely edentulous patients visiting the Department of Prosthodontic,
1Department of Dentistry, Patna Medical College and Hospital, Patna, Bihar, India

${ }^{2}$ Department of Dentistry, Vardhaman Institute of Medical Sciences, Pawapuri, Bihar, India

${ }^{3}$ Department of Conservative Dentistry, Buddha Institute of Dental Sciences and Hospital, Patna, Bihar, India

4,5 Department of Orthodontics and Dentofacial Orthopedics, Buddha Institute of Dental Sciences and Hospital, Patna, Bihar, India

${ }^{6}$ Department of Oral Medicine and Radiology, Jawahar Lal Nehru Medical College and Hospital, Bhagalpur, Bihar, India

Corresponding Author: Vikas Vaibhav, Department of Dentistry, Vardhaman Institute of Medical Sciences, Pawapuri, Bihar, India, Phone: +91 7259998190, e-mail: kunalkumar9380@gmail.com

How to cite this article: Kumar K, Vaibhav V, Singh AK, et al. Correlation of Depression with Edentulism in Elderly Patients. Int J Prosthodont Restor Dent 2020;10(3):112-114.

Source of support: Nil

Conflict of interest: None

Bridge and Crown Work for the replacement of teeth after obtaining the approval from the institutional ethics committee. The informed consent was obtained from all the participants.

The selection of patients was a simple random technique done by the lottery method. In all subjects, gender, age, education level, socioeconomic status, and marital status were noted. A thorough oral examination was performed. All patients were given Personal Health Questionnaire-8 (PHQ-8) ${ }^{8}$ to assess the depression level. It consists of nine questions on which the Diagnostic and Statistical Manual of Mental Disorders-4th Edition-Revised Text (DSM-IV-TR) diagnosis of depressive disorders is based. We used first eight

(0) Jaypee Brothers Medical Publishers. 2020 Open Access This article is distributed under the terms of the Creative Commons Attribution 4.0 International License (https://creativecommons.org/licenses/by-nc/4.0/), which permits unrestricted use, distribution, and non-commercial reproduction in any medium, provided you give appropriate credit to the original author(s) and the source, provide a link to the Creative Commons license, and indicate if changes were made. The Creative Commons Public Domain Dedication waiver (http://creativecommons.org/publicdomain/zero/1.0/) applies to the data made available in this article, unless otherwise stated. 
questions and we recorded the number of days patient experienced depressive symptoms in last 2 weeks. It was interpreted as $0-1$ day $=$ not at all, $2-6$ days $=$ several days, $7-11$ days $=$ more than half the days, and 12-14 days = nearly each day. Aggregate score was considered for PHQ-8. Patients with score that ranged from 0 to 4 were labeled with no significant depressive symptoms, score between 5 and 9 were labeled as mild depressive symptoms, score between 10 and 14 represented moderate depressive symptoms, 15 and 19 as moderately severe, and 20 and 24 showed severe depressive symptoms. The data were tabulated and statistically analyzed with SPSS (IBM, Chicago, Illinois, version 19.0). Two logistic regression models were performed at significance level $<0.05$.

\section{Results}

Table 1 shows that out of 530 patients, males were 280 (52.8\%) and females were 250 (47.2\%). Total 280 (52.8\%) had low socioeconomic status, 170 (32.0\%) had middle, and 95 (17.9\%) had high socioeconomic status. Total 275 (51.8\%) patients had education up to primary standard, 170 (32.0\%) had high, and 105 (19.2\%) had secondary standard. Total 502 (94.8\%) patients were married and 28 (5.2\%) were unmarried. All variables showed statistically significant difference $(p<0.05)$. Table 2 shows application of patient health questionnaire (PHQ-8) scoring and interpretation with behavioral risk factor surveillance survey (BRFSS) response conversion; most of the patients $(60.2 \%)$ had score more than 15 , which suggests that patients had depression symptoms. Table 3 shows that edentulism was significantly associated with socioeconomic status (OR 1.02, $95 \% \mathrm{Cl}=0.94-2.06)$, education level (OR 1.0, 95\% Cl = 0.98-1.72), marital status (OR $1.14,95 \% \mathrm{Cl}=1.08-2.34)$, and depression (OR $1.50,95 \% \mathrm{Cl}=1.24-2.14)$.

\section{Discussion}

There have been rise in cases of edentulism, with the increase in life expectancy. Older individuals tend to lose teeth more commonly

Table 1: Distribution of patients based on gender

\begin{tabular}{lll}
\hline Parameters & Variables & Number (\%) \\
\hline Gender & Male & $280(52.8)$ \\
Socioeconomic status & Female & $250(47.2)$ \\
& Low & $280(52.8)$ \\
& Middle & $170(32.0)$ \\
Education & High & $95(17.9)$ \\
& Primary & $275(51.8)$ \\
Marital status & High & $170(32.0)$ \\
& Secondary & $105(19.2)$ \\
& Married & $502(94.8)$ \\
\hline
\end{tabular}

compared to young ones. ${ }^{9}$ Several factors such as marital status, socioeconomic status, psychiatric illness, etc., play a major role. ${ }^{10,11}$ This study aimed to assess the edentulism in elderly subjects and its correlation with depression.

In the present study, we included 530 completely edentulous patients, which comprised of 280 males and 250 females. Total 280 (52.8\%) had low socioeconomic status, 170 (32.0\%) had middle, and 95 (17.9\%) had high socioeconomic status. Total 275 (51.8\%) patients had education up to primary standard, 170 (32.0\%) had high, and 105 (19.2\%) had secondary standard. Total 502 (94.8\%) patients were married and 28 (5.2\%) were unmarried. Saman et al. did a study to evaluate role of depression and rural residency in edentulism and concluded that depression and rural residency were the important factors related to partial and full edentulism following controlling for possible confounders. ${ }^{12}$

In our study, most of the patients (60.2\%) had scored more than 15 suggestive of depression symptoms. Okoro et al. in their survey observed that $56.1 \%$ population had tooth loss. They establish that patients with depression had a significantly higher prevalence of nonuse of oral health services the last few years than those without this disorder $(p<0.001)$. It was perceived that adults with depression and anxiety were more likely to have tooth loss. Adults with prevailing depression, lifetime diagnosed depression, and lifetime established anxiety were significantly more likely to have had at least one tooth removed than those without each of these disorders ( $p<0.001$ for all), after fully regulated for estimated confounders. $^{13}$

We established that edentulism was expressively related with socioeconomic status (OR $1.02,95 \% \mathrm{Cl}=0.94-2.06)$, education

Table 3: Bivariate analysis of patients

\begin{tabular}{llll}
\hline & \multicolumn{3}{c}{$\begin{array}{l}\text { Unadjusted } \\
\text { odds ratio }(95 \%\end{array}$} \\
Parameters & Variables & Cl) & p value \\
\hline Gender & Male & 1.14 & 0.94 \\
& Female & 1.18 & \\
Socioeconomic & Low & 1.56 & 0.01 \\
status & Middle & 1.12 & \\
& High & 1.02 & \\
Education & Primary & 1.12 & 0.021 \\
& High & 1.0 & \\
& Secondary & 1.68 & \\
Marital status & Married & 2.30 & 0.001 \\
& Unmarried & 1.14 & \\
Scale & PHQ-8 score & 1.50 & 0.03 \\
& (depression) & & \\
\hline
\end{tabular}

Table 2: Patient health questionnaire (PHQ-8) scoring and interpretation with BRFSS response conversion

\begin{tabular}{|c|c|c|c|c|c|c|c|c|}
\hline Questions & $\begin{array}{l}\text { Limited interest } \\
\text { in doing work } \\
\text { (\%) }\end{array}$ & $\begin{array}{l}\text { Subjects with feeling } \\
\text { of depression, } \\
\text { hopelessness (\%) }\end{array}$ & $\begin{array}{l}\text { Difficulty in } \\
\text { sleeping or } \\
\text { long sleep (\%) }\end{array}$ & Tiredness (\%) & $\begin{array}{l}\text { Anorexia or } \\
\text { excessive } \\
\text { eating (\%) }\end{array}$ & $\begin{array}{l}\text { Self bad } \\
\text { feeling (\%) }\end{array}$ & $\begin{array}{l}\text { Difficulty in } \\
\text { concentration } \\
\text { in work (\%) }\end{array}$ & $\begin{array}{l}\text { Speaking or } \\
\text { moving so } \\
\text { slowly (\%) }\end{array}$ \\
\hline $0-1$ days & 20 & 20 & 42 & 22 & 15 & 10 & 25 & 25 \\
\hline $2-6$ days & 25 & 32 & 16 & 18 & 16 & 12 & 20 & 18 \\
\hline 7-11 days & 35 & 18 & 22 & 32 & 36 & 23 & 20 & 22 \\
\hline 12-14 days & 20 & 30 & 20 & 28 & 37 & 50 & 35 & 35 \\
\hline
\end{tabular}


level (OR 1.0, 95\% Cl =0.98-1.72), marital status (OR 1.14, 95\% $\mathrm{Cl}=1.08-2.34$ ), and depression (OR $1.50,95 \% \mathrm{Cl}=1.24-2.14$ ). Latif et al. ${ }^{14}$ in their study on 5,392 patients, 100 subjects were included. It was observed that smoking prevalence was $73 \%$; hypertension, diabetes, and HIV+ prevalence were $26 \% 13$, and $5 \%$, respectively. About $41 \%$ were found to be with history of depression/psychiatric illness. About 55\% were taking three or more medications, $32.8 \%$ were taking five or more, and $22.4 \%$ were on seven or more. Author found an association between depression and edentulism.

Tyrovolas et al. ${ }^{15}$ evaluated the incidence of edentulism and its association with depression and self-rated health. Edentulism was significantly associated with depression (OR $1.57,95 \% \mathrm{Cl}$ $=1.23-2.00)$ and deprived self-rated health (OR $1.38,95 \% \mathrm{Cl}=$ 1.03-1.83) in the younger group with no considerable associations in the older age group.

Ghiță et al. evaluated the prevalence of different types of partial edentulism and the description of the various parameters. They observed increased frequency among the young population for partial edentulism forms (Kennedy III class). ${ }^{16}$

Psychiatric illness such as depression is quite common among elderly. Valuation of depression symptoms and suitable management of such symptoms may be supportive in reducing the cases of tooth loss. A large-scale survey emphasizing the evaluation of depression among elderly is required.

The disadvantage of this study is less sample range. Other factors such as smoking, alcoholism, medical illnesses, etc., which have harmful deleterious effect on the body as well as on the oral cavity were not taken under consideration. The inclusion of all such parameters could have been useful in achieving better results.

\section{Conclusion}

The present study indicates that edentulism was more predominant among patients with poor socioeconomic condition, married, and patients with education status up to the primary level. Depression has harmful effect in patients. Most of the patients had depression; this indicates the association of depression with tooth loss.

\section{Patients Consent}

Obtained

\section{Ethical approval}

Obtained from institutional ethics committee.

\section{References}

1. Nordenram G, Davidson T, Gynther G, et al. Qualitative studies of patients' perceptions of loss of teeth, the edentulous state and prosthetic rehabilitation: a systematic review with metasynthesis. Acta Odontol Scand 2015;71(3-4):937-951. DOI: 10.3109/ 00016357.2012.734421.

2. Nagaraj E, Mankani N, Madalli P, et al. Socioeconomic factors and complete edentulism in north Karnataka population. J Indian Prosthodont Soc 2014;14(1):24-28. DOI: 10.1007/s13191-012-0149-2.

3. Mai X, Wactawski-Wende J, Hovey KM, et al. Associations between smoking and tooth loss according to the reason for tooth loss: the Buffalo OsteoPerio study. J Am Dent Assoc 2013;144(3):252-265. DOI: 10.14219/jada.archive.2013.0112.

4. Khazaei S, Keshteli AH, Feizi A, et al. Epidemiology and risk factors of tooth loss among iranian adults: Findings from a large community-based study. Bio Med Res Int 2013;2013:786462. DOI: 10.1155/2013/786462.

5. Hamano T, Takeda M, Tominaga K, et al. Is accessibility to dental care facilities in rural areas associated with number of teeth in elderly residents? Int J Environ Res Public Health 2017;14(3):327. DOI: 10.3390/ ijerph14030327.

6. Bachkati $\mathrm{KH}$, Mortensen EL, Bronnum-Hansen $\mathrm{H}$, et al. Midlife cognitive ability, education, and tooth loss in older danes. J Am Geriatr Soc 2017;65(1):194-199. DOI: 10.1111/jgs.14513.

7. Kisely S, Sawyer E, Siskind D, et al. The oral health of people with anxiety and depressive disorders - a systematic review and metaanalysis. J Affect Disord 2016;200:119-132. DOI: 0.1016/j.jad.2016.04.040.

8. Kroenke K, Strine TW, Spitzer RL, et al. The PHQ-8 as a measure of current depression in the general population. J Affect Disord 2009;114(1-3):163-173. DOI: 10.1016/j.jad.2008.06.026.

9. Rodrigues SM, Oliveira AC, Vargas AMD, et al. Implications of edentulism on quality of life among elderly. Int J Environ Res Public Health 2012;9(1):100-109. DOI: 10.3390/ijerph9010100.

10. Quine S, Morrell S. Hopelessness, depression and oral health concerns reported by community dwelling older Australians. Community Dent Health 2009;26(3):177-182.

11. Khajuria R, Sudan S, Sharma S, et al. To assess the relation between depression and tooth loss - a questionnaire survey. J Appl Dent Med Sci 2018;4:1.

12. Saman DM, Lemieux A, Arevalo O, et al. A population-based study of edentulism in the US: does depression and rural residency matter after controlling for potential confounders? BMC Public Health 2014;14(1):65. DOI: 10.1186/1471-2458-14-65.

13. Okoro CA, Strine TW, Eke PI, et al. The association between depression and anxiety and use of oral health services and tooth loss. Community Dent Oral Epidemiol 2012;40(2):134-144. DOI: 10.1111/j.16000528.2011.00637.x.

14. Latif TM, Vieira AR. Risk factors and comorbidities associated with complete edentulism in individuals younger than fifty years of age. J Dentis Oral Health 2017;1(1):1.

15. Tyrovolas S, Koyanagi A, Panagiotakos D, et al. Population prevalence of edentulism and its association with depression and self-rated health. Sci Rep 2016;6(1):37083. DOI: 10.1038/srep37083.

16. Ghiță R, Scrieciu M, Mercuț V, et al. Statistical aspects of partial edentulism in a sample of adults in Craiova, Romania. Curr Health Sci J 2019;45(1):96-103. DOI: 10.12865/CHSJ.45.01.13. 